\title{
Cardiorespiratory patterns in siblings of babies with sudden infant death syndrome
}

\author{
D P SOUTHALl, J R ALEXANDER, V A STEBBENS, V G TAYLOR, AND \\ R E JANCZYNSKI
}

School of Mathematics, Statistics and Computing and School of Biological Sciences, Thames Polytechnic, London, and Department of Paediatrics Cardiothoracic Institute, Brompton Hospital, London

SUMMARY Clinical data and 24 hour tape recordings of electrocardiogram (ECG) and abdominal breathing movements were collected from 301 infants who had had a sibling who had suffered the sudden infant death syndrome (SIDS). Of these, 261 were referred cases, and 40 were recorded prospectively as part of a population based study; none of the 301 subsequently died. Fifty five of the referred siblings who had been born at full term ( $\geqslant 37$ week gestation) were randomly selected for a detailed analysis of heart rate and breathing patterns, as were all siblings born at full term from the prospective study (16 with a previous sibling in whom SIDS had occurred and seven with a sibling born at full term and in whom SIDS had subsequently occurred). The control group consisted of 197 recordings on 170 infants born at full term and matched by postnatal age.

The mothers of the siblings smoked and consumed alcohol more often during pregnancy than the mothers of control babies. The siblings had lower Apgar scores and were more often breast fed than controls.

There were no significant differences in the number of apnoeic pauses in the quantities of periodic breathing or in the heart and respiratory rates during regular breathing between the siblings and the controls.

In seeking to understand the pathophysiology of SIDS the subsequent siblings of cases of SIDS provide an easily accessible group for study. A recent population based epidemiological study, however, has shown that their individual risk is low and it seems unlikely that the investigation of small numbers of infants who have lost a sibling to SIDS will provide helpful information. ${ }^{1}$ Papers have been published describing higher respiratory rates in subsequent siblings than in controls, ${ }^{2-3}$ while others have failed to reproduce these findings. ${ }^{4-5}$ Some of the reports we studied described more short apnoeic pauses in subsequent siblings; ${ }^{6-9}$ others reported fewer in this group. ${ }^{2}$ Although Kelly et al ${ }^{10}$ reported more examples of periodic breathing in siblings, this was not confirmed by Flores-Guevara et al. $^{7}$

In an attempt to resolve these conflicting findings we analysed heart rate and breathing patterns on 24 hour tape recordings of ECG and abdominal breathing movements on 78 siblings of cases of SIDS who had been born at full term ( $\geqslant 37$ weeks' gestation), and 170 age matched controls who had also been born at full term. We also include a comparison of prenatal and early postnatal clinical data between these 78 siblings and their 170 controls.

\section{Patients}

Controls. A total of 197 24-hour tape recordings of ECG and abdominal wall movements were performed on 170 control infants. These infants were born at one of four hospitals, were born at full term ( $\geqslant 37$ weeks' gestation), and were chosen to cover the same age range as the siblings. A proportion was from a previously reported sequential control group $;{ }^{11}$ a second group was randomly selected from surviving infants being studied as part of a prospective investigation into SIDS; ${ }^{12}$ and a small group of older infants was chosen randomly from a local health visitors' clinic in Doncaster.

Prenatal and early postnatal clinical data were compiled from hospital notes and questionnaires given to parents at the time of the recordings. Four 
of the 170 controls were from twin pregnancies. Social class was assessed according to the employment of the major wage earner in the family. ${ }^{13}$ The social class of the control group (but not the siblings) was compared with national statistics from the 1981 census to check that they were representative. ${ }^{14}$

Siblings of cases of SIDS: A total of 301 siblings were studied, all of whom were followed up from the England and Wales central death register based at the Office of Population, Censuses, and Surveys.

The subgroup undergoing comparison with the control group consisted of 78 cases chosen from two sources. Fifty five cases were referred for clinical assessment ( 45 by consultant paediatricians, four by family practitioners, and six by parents), and 23 were part of a prospective population based study of SIDS. ${ }^{12}$ The 55 referred cases were randomly selected from the subgroup born at full term of the 261 cases referred to the Brompton Hospital over four years. The remaining 23 comprised the cases born at full term from the population based study; there were 17 babies born preterm who were not studied. ${ }^{12}$ This group of 23 was subdivided into 16 with a previous sibling who had had SIDS and seven in whom follow up of the family showed the sudden unexplained death of a subsequent sibling.

Five infants were twins of an infant who had had SIDS; the remainder were single births. Six of the referred cases and one of the population based group had more than one previous sibling who had died as a result of SIDS; one of the referred cases had had three previous siblings die of SIDS.

Of the 78 cases of SIDS whose siblings we studied physiologically, 61 deaths were verified as SIDS by necropsy reports from coroners or pathologists. In 17 cases summaries from the hospitals referring the siblings stated that SIDS was the cause of death, but it was not possible to obtain copies of necropsy reports.

The physiological data comprised 89 recordings: 59 on the 55 referred cases; 21 on the 16 population based group in which a previous sibling had died; and nine on the seven population based group in

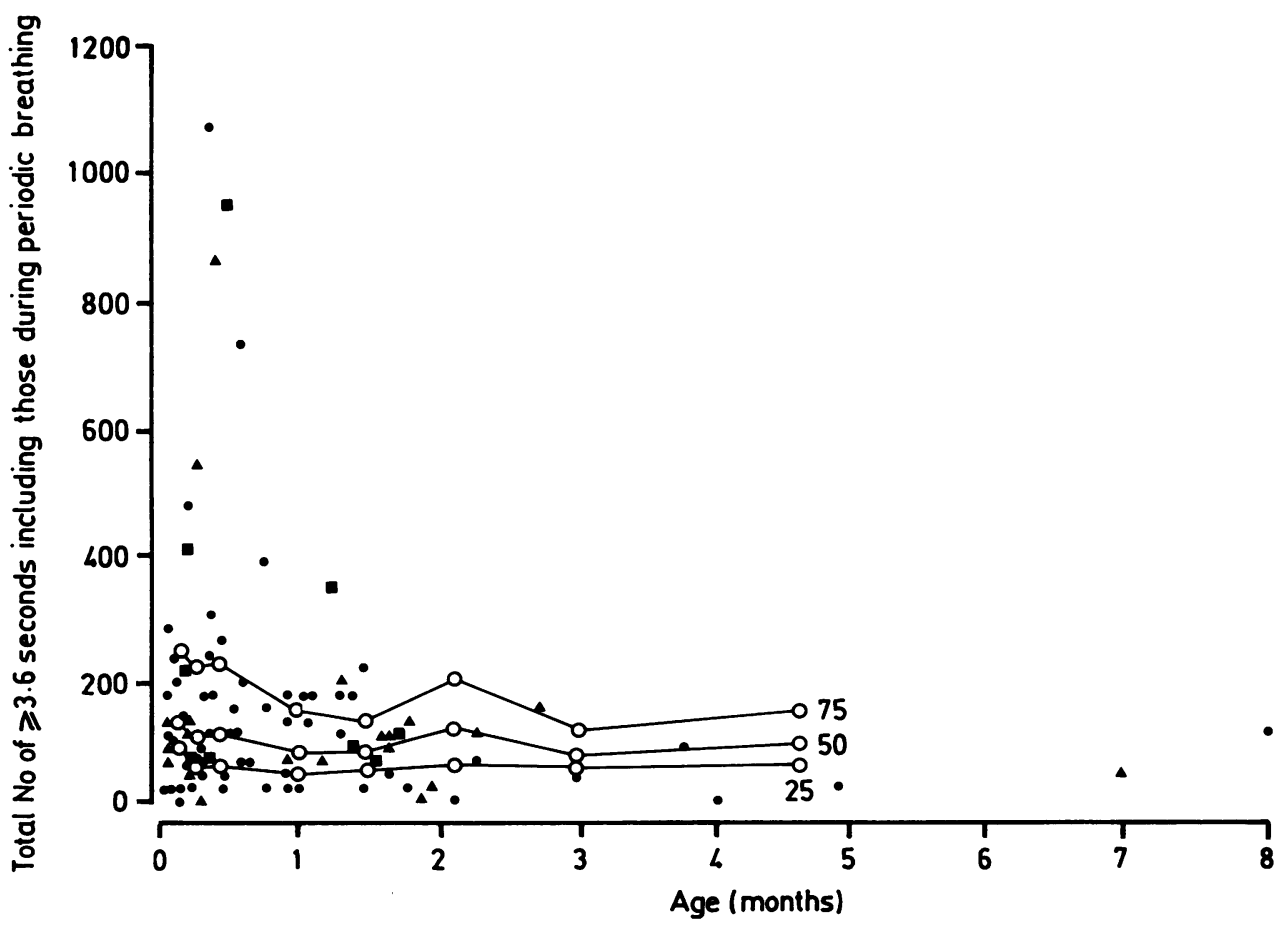

Fig. 1 Total No of apnoeic pauses for recording plotted against postnatal age. For controls, 25th, 50th, and 75th group centile values are plotted at median age of each group. Values for apnoeic pauses on each individual recording for each sibling are plotted at age of that recording: $\mathbf{O}=$ siblings referred for investigation; $\boldsymbol{\Delta}=$ population based cases recorded after previous sibling had died of SIDS; $\mathbf{0}=$ population based cases recorded before future sibling had SIDS. 
which a future sibling died. Clinical data comparable with those for the control group were collected on the 78 cases.

\section{Methods}

All recordings in cases and controls contained more than 18 hours of adequate breathing movement and heart rate signals. Full details of the recording and analysis procedures used in the study have been reported previously. " In summary, a 24 hour tape recording of ECG and abdominal wall movements, the latter from a pressure capsule transducer, was performed on each sibling and each control.

Recordings on the siblings were performed either in the hospital ward or, in most cases, at home; the recorder was sent home with the infant and returned 24 hours later. Only 3\% of controls underwent recordings in hospital.
Each recording was printed on to chart paper, as described in our previous report, ${ }^{11}$ and then measured and analysed blind by three technicians. The variables measured are listed below.

The number of apnoeic pauses $\geqslant 3.6$ seconds in duration per recording were counted and categorised according to their duration-that is, $\geqslant 3 \cdot 6-6 \cdot 0$ seconds and $>6 \cdot 0-12 \cdot 0$ seconds, and the duration of the overall longest pause per recording was also measured. Periodic breathing and periodic apnoea were defined as reported earlier, ${ }^{1}$ and the total duration of each and the longest single episode of periodic breathing were measured for each recording. Regular breathing was also defined as reported earlier ${ }^{11}$ but a more stringent definition was adopted for this measurement. Both heart and respiratory rates were measured over periods of one minute during each episode of regular breathing, avoiding pauses and sighs, and an average taken for the

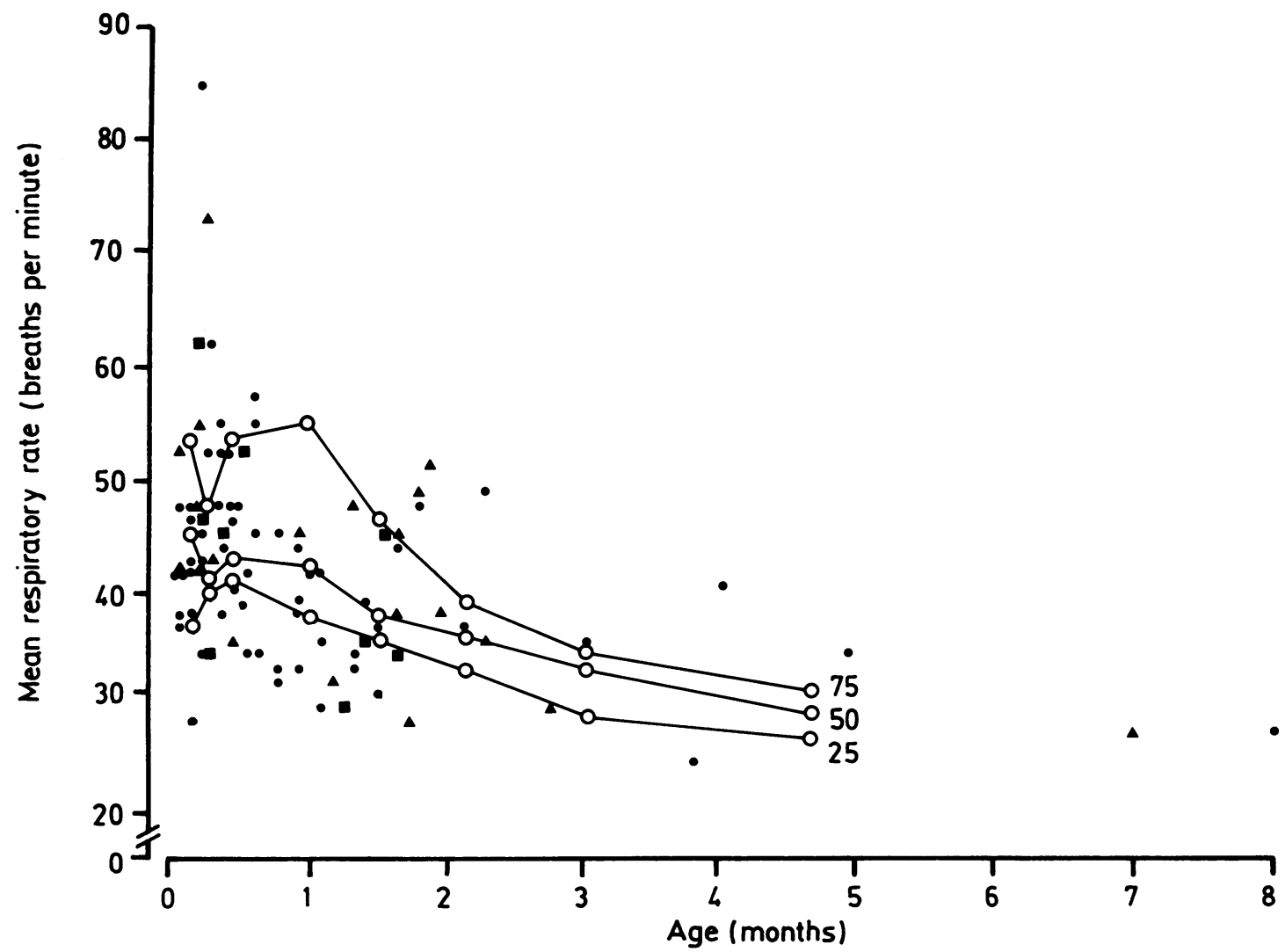

Fig. 2 Mean respiratory rate during regular breathing for each recording plotted against age at time of recording. For controls, 25th, 50th, and 75th group centile values are plotted at median age of each group. Values for apnoeic pauses on each individual recording for each sibling are plotted at age of that recording: $=$ siblings referred for investigation; $\boldsymbol{\Delta}=$ population based cases recorded after previous sibling had died of SIDS; $\mathbf{\square}=$ population based cases recorded before future sibling had SIDS. 
whole recording. Where appropriate, measurements were adjusted to account for artefact and varying lengths of recording, to a nominal 22 hours (the average).

Comparison of clinical data on siblings and controls was by Student's $t$ test, Fisher's exact test, or the $\chi^{2}$ test, as appropriate.

Comparison of physiological data on siblings and controls was by the Van-Elteran modified Wilcoxon rank sum test for stratified data. ${ }^{15}$

The following 15 clinical variables were compared between cases and controls: for each mother her age at the time of the birth, the social class of her family, her smoking and alcohol consumption during pregnancy, any serious medical problems or complications of the pregnancy, any medication taken during pregnancy, and the mode of delivery of her infant; and for each infant the Apgar scores at one and five minutes, sex, gestational age and birth weight, the reception of resuscitation at birth, and mode of feeding at the time of recording.

\section{Results}

A comparison of clinical variables showed that the mothers of siblings smoked and consumed alcohol more often during pregnancy $(p<0.01$ and $p<0.05$, respectively). The mothers of siblings more often had a history of serious medical problems $(p<0.05)$ but took less medication during pregnancy $(p<0 \cdot 05)$. Compared with controls there was no difference in birth weights or Apgar scores at one minute, but more of the sibling cases were breast fed $(p<0 \cdot 01)$. At five minutes the Apgar scores were lower in siblings $(\mathrm{p}<0 \cdot 05)$. A comparison of occupational origins of the siblings with controls and those of controls with the general population showed no significant differences.

When measurements of apnoeic pauses, periodic breathing, regular breathing, and heart and respiratory rates during regular breathing were compared between siblings and controls, siblings tended to have more short apnoeic pauses and higher respira-

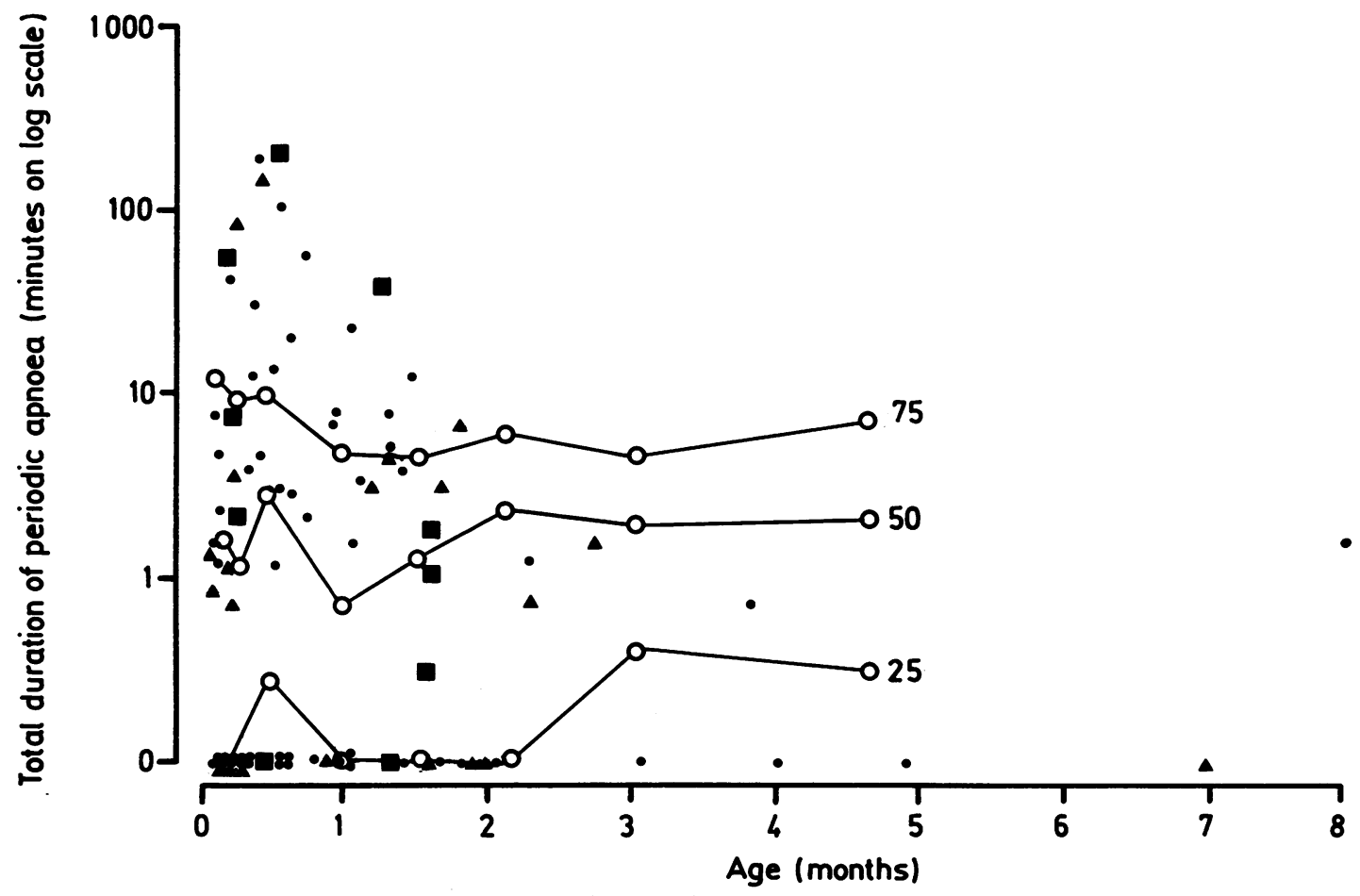

Fig. 3 Total duration of periodic apnoea per recording on a logarithmic scale is plotted against age at time of recording. For controls, 25th, 50th, and 75th group centile values are plotted at median age of each group. Values for apnoeic pauses on each individual recording for each sibling are plotted at age of that recording: $=$ siblings referred for investigation; $\boldsymbol{\Delta}=$ population based cases recorded after previous sibling had died of SIDS; $\mathbf{\square}=$ population based cases recorded before future sibling had SIDS. 


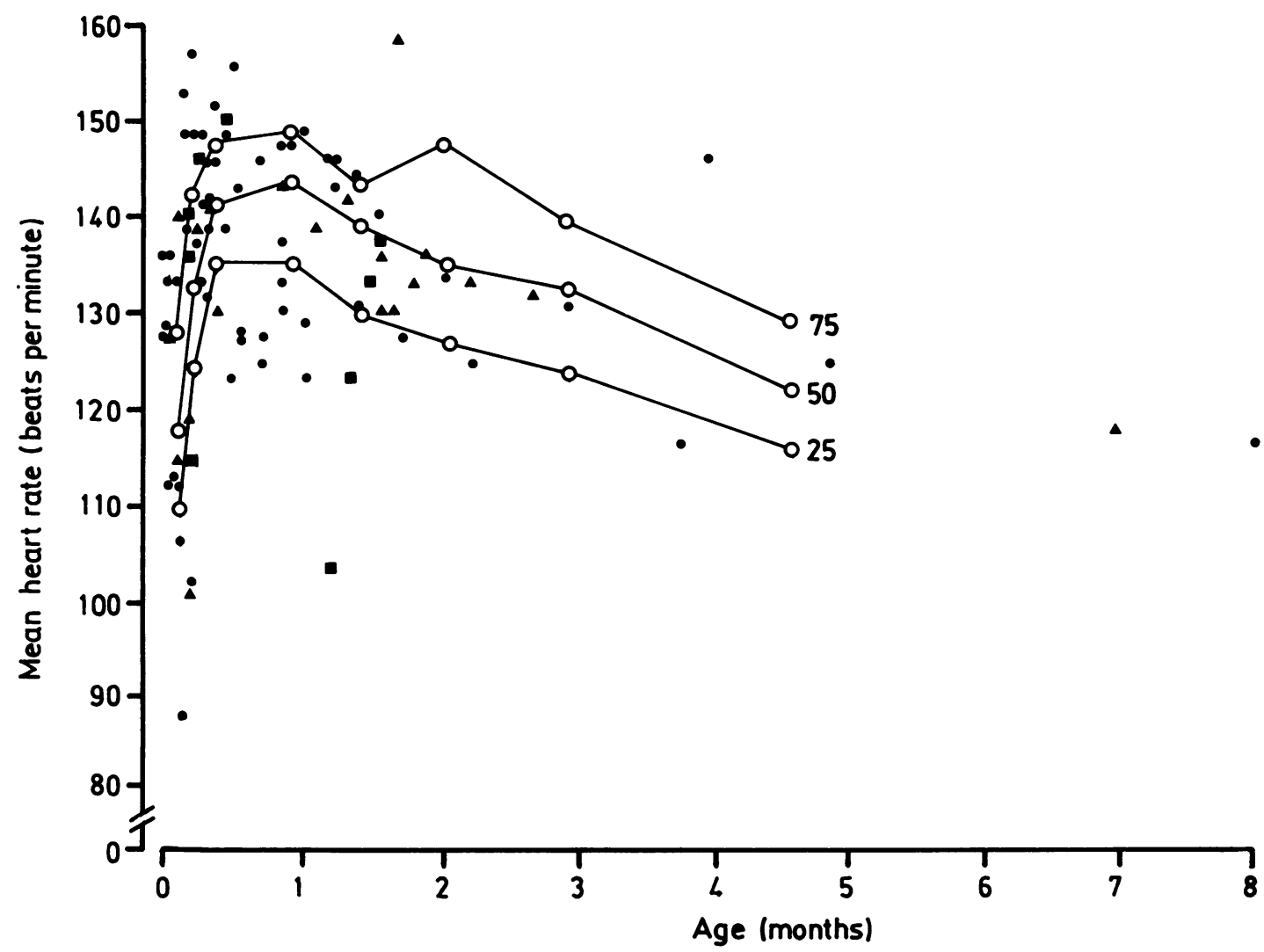

Fig. 4 Mean heart rate during regular breathing for each tape recording plotted against age at time of recording. For controls, 25th, 50th, and 75th group centile values are plotted at median age of each group. Values for heart rate on each individual recording for each sibling are plotted at age of that recording: $\mathrm{O}=$ siblings referred for investigation; $\mathbf{\Delta}=$ population based cases recorded after previous sibling had died of SIDS; $\mathbf{\square}=$ population based cases recorded before future sibling had SIDS.

tory rates than controls (Figs. 1 and 2). These apparent differences were not, however, significant $(\mathrm{p}>0.05)$, nor were the levels of periodic breathing or quantities of regular breathing, or heart rates during regular breathing, significantly different between siblings and controls ( $p>0.05)$ (Figs. 3 and 4$)$.

\section{Discussion}

This study has failed to show any group differences between siblings of cases of SIDS and controls in the quantities of periodic or regular breathing and measurements of apnoeic pauses or heart and respiratory rates during regular breathing.

Our findings concerning respiratory rates complement those of Curzi-Dascalova et al ${ }^{4}$ who found no significant group differences and showed a wide variability in values.
Although we have been unable to confirm the results of Hoppenbrouwers et $a l^{2}$ and Carse et al, ${ }^{3}$ who found higher respiratory rates in siblings, our results do not contradict theirs and, particularly at the younger ages, our siblings showed a tendency in this direction. We did not, however, find any evidence to support the conclusions of Harper et $a l^{16}{ }^{17}$ that the heart rate is increased in siblings. We consider that the most likely explanation for this discrepancy lies in the wide variability in heart rates in normal infants. A second possibility is that the regular breathing state may not be concordant with quiet sleep.

Kelly et $a l^{10}$ reported increased levels of periodic breathing and, in active sleep, increased numbers of apnoeic pauses ${ }^{6}$ in subsequent siblings of cases of SIDS. Flores-Guevara $\mathrm{et}^{\mathrm{al}} \mathrm{l}^{7}$ found no differences in periodic breathing and Hoppenbrouwers et $a l^{2}$ 
reported reduced numbers of apnoeic pauses in indeterminate sleep in siblings. We could not show any significant group differences in these variables although, in the recordings made soon after birth, the siblings seemed to have had slightly larger numbers of short apnoeic pauses.

One group of interest in our study was that of infants from the prospective study whose subsequent siblings had SIDS. At the time of their recordings the parents were unaware that their infant's future sibling was at increased risk of subsequent SIDS. Although this particular group was relatively small, no difference in the physiological variables was identified between the latter and those cases where a previous sibling had died of SIDS.

Smoking and alcohol intake during pregnancy and serious maternal medical problems were more prevalent in siblings of SIDS babies than in controls. Some of these variables have been previously noted to be overrepresented in mothers of infants who had SIDS. ${ }^{18}$

In conclusion, the analyses we have performed on heart rate and breathing movement patterns in this group of siblings of cases of SIDS failed to identify measurements which distinguish them from normal infants. Perhaps this is not surprising in view of the small magnitude of increased risk of SIDS in this group of infants ${ }^{1}$ and the failure of this particular kind of analysis to predict SIDS in a prospective population based study. ${ }^{19}$

We are grateful to the Foundation for the Study of Infant Death (FSID). Healthdyne, Smith's Charity. Dr Southall was supported by the British Heart Foundation, the Waring Scholarship, Healthdyne, the National SIDS Foundation. Nellcor, the Joseph Levy Foundation; Valeric Stebbens was funded by FSID and the Nuffield Foundation. We thank Pauline Mills, Jackie Kelly, and Wendy Yates who made the primary measurements on the physiological data, and Katy Sowton who typed the manuscript.

\section{References}

' Irgens LM. Skjaerven R. Peterson DR. Prospective assessment of recurrence risk in sudden infant death syndrome siblings. $J$ Pediatr 1984:104:349-51.

2 Hoppenbrouwers T. Hodgman JE, McGinty D. Harper RM, Sterman MB. Sudden infant death syndrome: sleep apnea and respiration in subsequent siblings. Pediatrics 1980;66:205-14.

${ }^{3}$ Carse EA, Henderson-Smart DJ, Johnson P. Whyte P, Wilkinson AR. Transcutaneous oxygen tension measurements during sleep in the newborn baby and infant. Arch Dis Child 1980;55:318.

4 Curzi-Dascalova L, Flores-Guevara R. Guidasci S, Korn G, Monod N. Respiratory frequency during sleep in siblings of sudden infant death syndrome victims. A comparison with control, normal infants. Early Hum Dev 1983;8:235-41.

Brady JP, McCann EM. Control of ventilation in subsequent siblings of victims of sudden infant death syndrome. J Pediatr 1985: 106:212-7.

${ }^{6}$ Kelly DH, Twanmoh J, Shannon DC. Incidence of apnea in siblings of sudden infant death syndrome victims studied at home. Pediatrics 1982:70:128-31.

${ }^{7}$ Flores-Guevara R, Curzi-Dascalova L. Radvanyi MF, et al. Respiratory pauses in normal infants and in siblings of victims of the sudden infant death syndrome. In: Buser PA, Cobb WA, Okuma T, eds. Kyoto Symposia (EEG Suppl No 36) Amsterdam: Elsevier Biomedical Press, 1982:631-40.

\& Nogues B, Samson-Dollfus D. Etude comparative de la respiration pendant le sommeil chez des bebés temoins et des bebés a risque de mort subite (enfants de 2 mois 1 an). Waking Sleeping 1979;3:263-71.

${ }^{9}$ Guillaume A, Navelet Y. Benoit. O. Les pauses respiratoires dans le sommeil nocturne du nourrisson. Arch Fr Pediatr 1981:38:673-7.

10 Kelly DH, Walker AM, Cahen L, Shannon DC. Periodic breathing in siblings of sudden infant death syndrome victims. Pediatrics 1980;66:515-520.

1 Richards JM. Alexander JR, Shinebourne EA, de Swiet M. Wilson AJ, Southall DP. Sequential 22 hour profiles of breathing pattern and heart rate in 110 full-term infants during their first 6 months of life. Pediatrics 1984:74:763-77.

12 Southall DP, Richards JM, de Swiet M. Identification of infants destined to die unexpectedly during early infancy: evaluation of predictive importance of prolonged apnoea and disorders of cardiac rhythm or conduction. First report of a multicentred prospective study into the sudden infant death syndrome. Br Med J 1983:286:1092-6.

13 Office of Population and Censuses and Surveys. Classification of occupations. London: HMSO, 1980.

14 Ramprakash D, Morris J eds. Social Trends No 15. London: HMSO, 1985.

15 Van Elteran PH. On the combination of independent 2 sample tests of Wilcoxon. Bull Inst Intern Statist 1960;37:351-61.

${ }^{16}$ Harper RM, Leake B, Hoppenbrouwers T, Sterman MB, McGinty DJ, Hodgman J. Polygraphic studies of normal infants and infants at risk for the sudden infant death syndrome: heart rate and variability as a function of state. Pediatr Res 1978:12:778-85.

${ }_{17}$ Harper RM, Leake B, Hodgman JE, Hoppenbrouwers T. Developmental patterns of heart rate and heart rate variability during sleep and waking in normal infants and infants at risk from the sudden infant death syndrome. Sleep 1982;5:28-38.

18 Merritt TA, Valdes-Dapena M. SIDS research update. Pediatr Ann 1984:13:193-207.

11) Southall DP, Richards JM, Stebbens VA, Wilson AJ, Taylor V. Alexander JR. Cardiorespiratory function in 16 full-term infants with sudden infant death syndrome. Pediatrics 1986;78:787-96.

Correspondence to Dr D P Southall, Department of Paediatrics, Cardiothoracic Institute, Brompton Hospital, London SW3 6HP.

Received 4 February 1987 